\title{
Screening of gestational diabetes mellitus using one-step versus two-step method: a comparative study
}

\section{Deepti Khenwar, Juhi Agarwal, Sushruta Shrivastava*}

Department of Obstetrics and Gynecology, Gandhi Medical College, Bhopal, Madhya Pradesh, India

\author{
Received: 04 June 2020 \\ Accepted: 06 July 2020 \\ *Correspondence: \\ Dr. Sushruta Shrivastava, \\ E-mail: vikrantsush18@gmail.com
}

Copyright: ( ) the author(s), publisher and licensee Medip Academy. This is an open-access article distributed under the terms of the Creative Commons Attribution Non-Commercial License, which permits unrestricted non-commercial use, distribution, and reproduction in any medium, provided the original work is properly cited.

\begin{abstract}
Background: Gestational diabetes mellitus (GDM) is defined as carbohydrate intolerance of variable severity with onset or first recognition during the present pregnancy. It affects $7 \%$ of all pregnancies worldwide and in India it ranges from 6 to $9 \%$ in rural and 12 to $21 \%$ in urban area. The aim of this study was to compare the DIPSI criteria with the two-step method (Carpenter and Couston criteria.) and to study merits and demerits of one step and two step tests for GDM.

Methods: A total 400 pregnant women of gestational age between 24-28 weeks attending antenatal clinic at this study tertiary care center were enrolled in this study. 200 pregnant women were enrolled in each of the study group (Group I OGTT and Group II DIPSI).

Results: In Group I (OGTT) screening 47 (23.5\%) were tested positive. In Group II cases, screening test results were found positive among 44 (22\%). Out of 95 high-risk pregnant women 38 (40\%) were positive for GDM by OGTT and $34(35.78 \%)$ were positive by DIPSI. Out of 305 non high-risk pregnant women, 9 (2.95\%) were positive for GDM by OGTT and $10(3.27 \%)$ were positive by DIPSI.

Conclusions: Present study concludes that DIPSI is the test which can predict GDM in population comparable to another test like OGTT. Also, India's major population reside in rural areas, ANC are mostly conducted by ANM, therefore screening test should be easy to perform and interpret.
\end{abstract}

Keywords: Diabetes in pregnancy study group of India, Gestational diabetes mellitus, Oral glucose tolerance test, One step method, Two step method

\section{INTRODUCTION}

Gestational diabetes mellitus (GDM) is defined as carbohydrate intolerance of variable severity with onset or first recognition during the present pregnancy. ${ }^{1}$

This definition includes women whose glucose tolerance will return back to normal after pregnancy and also those who will persist with glucose intolerance and develop type 2 diabetes. It affects $7 \%$ of all pregnancies worldwide and in India it ranges from 6 to $9 \%$ in rural and 12 to $21 \%$ in urban area. ${ }^{2}$ The high rate implies that Indian population has a higher incidence of DM and impaired glucose tolerance and is at a greater risk of developing GDM. It is diagnosed at $16.3 \%$ in $\leq 16$ weeks of gestation, $22.4 \%$ between $17-23$ weeks and $61.3 \%$ after 23 weeks of gestation. ${ }^{3}$

High prevalence of DM and genetic predisposition to metabolic syndrome among Asians, particularly in Indian women, predisposes women to develop GDM and its complications. So, there is a need for cost-effective universal screening and diagnostic method.

\section{METHODS}

Pregnant women of gestational age between 24-28 weeks attending antenatal clinic at the study tertiary care center. 
200 pregnant women were enrolled in each of the study group.

\section{Inclusion criteria}

- Singleton pregnancy with low or average risk for GDM

- Maternal age of 18 years or more and,

- Gestational age between 24 and 28 weeks of gestation, based on regular menstrual period and ultrasound examination in the first half of pregnancy.

\section{Exclusion criteria}

- History of overt diabetes in current pregnancy

- History of intake of drugs that affects glucose metabolism like corticosteroids, progesterone and beta-agonist

- Patient who refused to undergo screening and diagnostic test for GDM.

\section{Methods followed in the study}

Details of age, religion, rural and urban, socio economic status, obstetric history, past history, family history of diabetes, previous pregnancy high risk, present pregnancy high risk, BMI of pregnant women between gestational age of 24-28 weeks was obtained.

Group I - pregnant women is given $50 \mathrm{gm}$ of glucose challenge test and blood sugar estimated at 1 hour a value of $140 \mathrm{mg} / \mathrm{dl}$ is considered as positive. One week she was given $100 \mathrm{mg}$ GTT and blood sugar estimated at fasting, 1 hour, 2 hour, 3 hours according to Carpenter and Couston criteria.

Group II - pregnant women is given 75 gm of glucose (DIPSI) and blood sugar estimated at 2 hours a value of $>140 \mathrm{mg} / \mathrm{dl}$ is considered as positive according to DIPSI.

\section{RESULTS}

Total 400 pregnant women were selected for the study. Out of 400 pregnant women, 200 underwent two step test OGTT (GCT and GTT) and 200 underwent one step test DIPSI (75 gm). Out of 200 OGTT cases, 25 pregnant women dropped and 175 completed the study. Demographic distribution of pregnant women according to type of procedure and age groups are mentioned in Table 1 . There was statistically not significant difference found in distribution of study subjects (pregnant women) according to age groups, religion and locality ( $\mathrm{p}>0.05)$.

Table 1: Demographic distribution of study subjects (pregnant women) according to type of procedure and age groups, religion, locality, obstetric index.

\begin{tabular}{|c|c|c|c|c|c|}
\hline Age groups & Total & $\begin{array}{l}\text { Group I } \\
\text { OGTT (GCT } 50 \text { gm and } \\
\text { GTT } 100 \text { gm) two step }\end{array}$ & $\begin{array}{l}\text { Group II } \\
\text { DIPSI ( } 75 \text { gm) } \\
\text { one step }\end{array}$ & $\begin{array}{l}\text { Chi square } \\
\text { value }\end{array}$ & $\begin{array}{l}\text { Significance } \\
\text { ' } p \text { ' value }\end{array}$ \\
\hline$<30$ year & $328(87.5 \%)$ & $151(86.3 \%)$ & $177(88.5 \%)$ & \multirow{2}{*}{1.25} & \multirow{2}{*}{$0.264(\mathrm{NS})$} \\
\hline$>30$ year & $47(12.5 \%)$ & $24(13.7 \%)$ & $23(11.5 \%)$ & & \\
\hline \multicolumn{6}{|l|}{ Religion } \\
\hline Hindu & $214(57.1 \%)$ & $96(48.0 \%)$ & $118(59.0 \%)$ & \multirow{2}{*}{0.654} & \multirow{2}{*}{0.419 (NS) } \\
\hline Muslim & $161(42.9 \%)$ & $79(52.0 \%)$ & $82(41.0 \%)$ & & \\
\hline \multicolumn{6}{|l|}{ Locality } \\
\hline Rural & $144(38.4 \%)$ & $63(36.0 \%)$ & $81(40.5 \%)$ & \multirow{2}{*}{0.799} & \multirow{2}{*}{0.371 (HS) } \\
\hline Urban & $231(61.6 \%)$ & $112(64.0 \%)$ & $119(59.5 \%)$ & & \\
\hline \multicolumn{6}{|c|}{ Obstetric history } \\
\hline G1 or Primi & $134(35.7 \%)$ & $73(41.7 \%)$ & $61(30.5 \%)$ & \multirow{2}{*}{5.11} & \multirow{2}{*}{0.024 (S) } \\
\hline Multi & $241(64.3 \%)$ & $102(58.3 \%)$ & $139(69.5 \%)$ & & \\
\hline Total & $375(100 \%)$ & $175(100 \%)$ & $200(100 \%)$ & & \\
\hline
\end{tabular}

Out of 400 pregnant women, $359(89.75 \%)$ had no significant high risk in present pregnancy. Hypertension was found in $10(5 \%)$ Group I cases and $3(1.5 \%)$ group II cases. Infection (Candidiasis) was found in $4(2 \%)$ Group I and $1(0.5 \%)$ Group II cases. Obesity was found in $10(5 \%)$ Group I and $8(4.0 \%)$ Group II cases. There was statistically no significant difference found in distribution of pregnant women according to type of procedure and present pregnancy high risk. $(\mathrm{p}=0.143)$ thus making study groups comparable (Table 2).

In Table 3 authors have summarize the result of screening test (OGTT and DIPSI) among the pregnant females. Out of 400 pregnant women, 200 underwent two step test OGTT (GCT and GTT) and 200 underwent one step test DIPSI (75 gm). Out of 200 OGTT subjects; GCT was done for 200 and in that 95 cases were positive and 105 
were negative. It was followed by GTT (100 gm) among 95 cases. Out of 95, 28 cases were lost to follow up and $47(23.5 \%)$ were positive and $20(10 \%)$ cases were negative. Out of 200 Group II cases, screening test results were found positive among $44(22 \%)$ and found negative among $156(78 \%)$. Result of Screening test were found more positive among Group I cases as compare to Group II cases (p value 0.001).

Table 2: Distribution of study subjects (pregnant women) according to high risk factors in present pregnancy excluding past pregnancy risk factors.

\begin{tabular}{|llll|}
\hline $\begin{array}{l}\text { Present pregnancy high } \\
\text { risk }\end{array}$ & Total & $\begin{array}{l}\text { Group I } \\
\text { OGTT (GCT 50 gm and GTT 100 gm ) } \\
\text { two step }\end{array}$ & $\begin{array}{l}\text { Group II } \\
\text { DIPSI (75 gm) } \\
\text { one step }\end{array}$ \\
\hline & $\mathbf{N}(\mathbf{\%})$ & $\mathbf{N}(\%)$ & $\mathbf{N}(\%)$ \\
\hline Not significant & $359(89.75 \%)$ & $172(86.0 \%)$ & $187(93.5 \%)$ \\
\hline Hypertension & $13(3.25 \%)$ & $10(5 \%)$ & $3(1.5 \%)$ \\
\hline Infection (Candidiasis) & $5(1.25 \%)$ & $4(2 \%)$ & $1(0.5 \%)$ \\
\hline Obesity & $18(4.5 \%)$ & $10(5 \%)$ & $8(4.0 \%)$ \\
\hline Polyhydramnios & $3(0.75 \%)$ & $2(1.0 \%)$ & $1(0.5 \%)$ \\
\hline Oligohydramnios & $2(0.5 \%)$ & $2(1.0 \%)$ & $0(0.0 \%)$ \\
\hline Significance 'p' value & $0.143(\mathrm{NS})$ & & \\
\hline
\end{tabular}

Table 3: Result of screening test (OGTT and DIPSI) among study subjects.

\begin{tabular}{|lllll|}
\hline Result of screening test & GCT $(\mathbf{5 0}$ gm) & GTT (100 gm) & DIPSI (75 gm) \\
\hline & N=200 & N=95 & N (\%) \\
\hline Positive & $95(47.5 \%)$ & Drop out & Positive & \\
\hline Negative & $105(52.5 \%)$ & $28(14 \%)$ & $47(23.5 \%)$ & $44(22 \%)$ \\
\hline Significance 'p' value & $0.001(\mathrm{~S})$ & $20(10 \%)$ & & $156(78 \%)$ \\
\hline
\end{tabular}

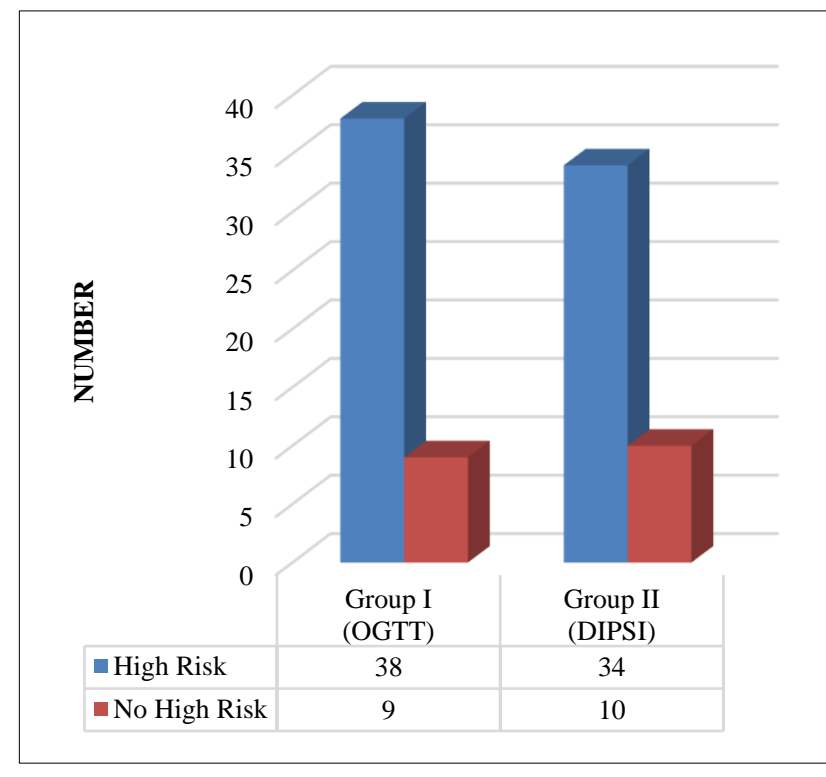

Figure 1: Comparison of positive results in high-risk and no high-risk groups.

Figure 1 summaries the result of comparison of positive results in high-risk group and no high-risk group subjects. Out of 95 high-risk pregnant women 38 (40\%) were positive for GDM by OGTT and 34 (35.78\%) were positive by DIPSI. Out of 305 non high-risk pregnant women, $9(2.95 \%)$ were positive for GDM by OGTT and $10(3.27 \%)$ were positive by DIPSI ( $\mathrm{p}$ value- 0.675 ; NS).

Table 4: Comparison of negative result in high-risk and no high-risk subjects.

\begin{tabular}{|lll|}
\hline & $\begin{array}{l}\text { Group I } \\
\text { (OGTT) }\end{array}$ & $\begin{array}{l}\text { Group II } \\
\text { (DIPSI) }\end{array}$ \\
\hline High-risk N=95 & $11(11.58 \%)$ & $12(12.63 \%)$ \\
\hline No high-risk N=305 & $114(37.38 \%)$ & $144(47.21 \%)$ \\
\hline \multicolumn{2}{|l|}{ Significant p value $0.736(\mathrm{NS})}$. \\
\hline
\end{tabular}

Table 5: Prevalence of GDM by one step and two step test.

\begin{tabular}{|lll|}
\hline Result & Group I (OGTT) & Group II DIPSI \\
\hline Positive & 47 & 44 \\
\hline Percentage & $27.32 \%$ & $22 \%$ \\
\hline p-value & $0.234(\mathrm{NS})$ & \\
\hline
\end{tabular}

Table 4 reveals comparison of negative results in highrisk and no high-risk groups Out of 95 high-risk pregnant women $11(11.58 \%)$ were negative for GDM by OGTT and $12(12.63 \%)$ were negative by DIPSI. Out of 305 non 
high-risk pregnant women, $114(37.38 \%)$ were negative for GDM by OGTT and $144(47.21 \%)$ were negative by DIPSI (p value- 0.736 ; NS).

\section{DISCUSSION}

The present study was conducted in a tertiary care center for screening gestational diabetes mellitus in antenatal females attending outdoor and inpatient by one step and two step method and comparing the results of each method. A total of 400 pregnant women were taken and 200 each were allocated in one step and two step tests. Out of 400 pregnant women, 200 underwent two step tests (OGTT (GCT and GTT) and 200 underwent one step test (DIPSI (75 gm)). Out of 200 OGTT cases, 28 pregnant women dropped out after $1^{\text {st }}$ step of GCT and weren't followed up for $2^{\text {nd }}$ step GTT, irrespective of the result and 172 subjects completed the study.

In present study out of 372 study subjects 91 females were diagnosed to be positive for GDM, making the prevalence to be $24.46 \%$ in the study population. Among the 372 females who completed the study $325(87.5 \%)$ were less than 30 years of age and only $47(12.5 \%)$ were between 30-35 years of age. In the Seshiah V et al study prevalence proportion increased with age from $14.5 \%$ in the age group of $15-19$ years to $25 \%$ in the age group of $>30$ years. ${ }^{4}$ There was no significant difference found statistically in distribution of pregnant women according to age groups, religion and locality $(p>0.05)$ but there was statistically significant difference found in distribution of pregnant women according to their obstetric history ( $\mathrm{p}=0.024)$. Out of 134 primigravida's, 20 (5\%) were found to be positive while out of 241 multigravidas $60(15 \%)$ were found to be positive. According to Seshiah $\mathrm{V}$ et al, the prevalence proportion of GDM increased with gravidity, from $16.3 \%(95 \%$ confidence limits: $12.7 \%-20.3 \%$ ) in primigravida to $25.8 \%$ (95\% confidence limits: $11.9 \%-44.6 \%$ ) in gravidas $>4 .^{4}$ Study conducted by $\mathrm{Xu} \mathrm{X}$ et al, concluded that the prevalence of GDM among all participants, women in the first pregnancy, and women in the second pregnancy were $3.7 \%, 3.4 \%$, and $4.6 \%$, respectively. ${ }^{5}$ This study result were consistent with other studies.

In the present study it was seen that 305 women were with no risk factors, still screening test detected GDM in 19 females $(6.2 \%)$ (Table 4), this shows that not only high-risk pregnant women but also low risk pregnant women have propensity to develop GDM, which can produce substantial adverse perinatal outcome. Hence, each and every pregnant woman should be screened for GDM.

In present study total no of positive cases by two step tests are $47(23.5 \%)$ and by one step test are $44(22 \%)$.

Result of both the group were consistent with various study. Result of Group I was consistent with Jiwani A et al, Sevket $\mathrm{O}$ et al. ${ }^{6,7}$
Result of Group II was consistent with Sharma A et al, Balaji et al. ${ }^{8,9}$ Both the tests were equally sensitive to detect GDM in community which is evident from the pvalue is 0.234 shows non-significant result (Table 5).

However, in present study in Group I, out of 200 OGTT subjects; GCT was done in all 200 subjects, out of which $95(47.5 \%)$ cases were found to be positive and 105 $(52.5 \%)$ were negative. It was followed by GTT (100 gm) among 95 cases. Out of 95, 28 (14\%) subjects dropped out, and $47(23.5 \%)$ cases were found to be positive and $20(21.05 \%)$ cases were negative. Result of Screening test were found more positive among Group I cases as compare to Group II cases. Though there was statistically significant difference found in result of screening test (OGTT and DIPSI) between Group I and II among study subjects $(\mathrm{p}=0.001)$ (Table 3$)$, but the number of dropout cases were also more in Group I i.e., 28 (14\%). Similar observation were seen in Seshiah V et al, and de Aguiar et al. ${ }^{4,10}$ This phenomenon in above mentioned study and present study, "no show" occurs because the women have to come to antenatal clinic more than once for the blood test, and number of times blood sample is withdrawn is also more in two step procedure which is not acceptable. Moreover, lesser frequency of pregnant women who seek for ANC in developing countries like ours adds to this trouble. The food for thought is about the study subjects who never came back for the second test and may be potential candidate for GDM. This defeats the purpose of universal screening which can be fulfilled by $100 \%$ acceptable one step test DIPSI. In this study authors have seen that there was no statistical difference seen in prevalence of GDM detected by two methods ( $p$-value 0.234 ; Table 5).

With a huge population in the reproductive age in India, a significant segment developing abnormal glucose tolerance is also a matter of concern. The selective screening recommended by ADA is not suitable for our country and authors should not only stress universal screening but also should not ignore impaired glucose tolerance. Authors should also consider impaired glucose tolerance as an independent risk factor for GDM. As in the present study total diagnosed case of GDM with DIPSI was $44(22.0 \%)$ and if authors decrease threshold from $140 \mathrm{mg} / \mathrm{dl}$ to $110 \mathrm{mg} / \mathrm{dl}$, the additional cases with impaired glucose tolerance were $41(20.5 \%)$ making a total cases of GDM to be $85(42.5 \%)$ which is just double of the result obtained by standard DIPSI guidelines. Similar results were in study done by Mohan V et al. ${ }^{11}$ In a study of Jowett et al, impaired glucose tolerance ranged from $25 \%$ to $45 \% .^{12}$ In a study of Sermer et al, emphasized increasing carbohydrate intolerance in woman without gestational diabetes was associated with a significant adverse maternal and perinatal outcome related to GDM. ${ }^{13}$ Hence multivariate analysis showed that increasing carbohydrate intolerance is an independent predictor for various unfavorable outcomes. So, it is always better to do a glucose challenge test (DIPSI) rather than doing a random blood sugar. 
It was also seen that despite of more female with high risk factor in Group I, the result of GDM screening was not significant statistically in both group (p-value 0.234 ; Table 5).

Thus, authors can say that DIPSI is better option for GDM screening, as recommended by WHO, it serves both as a screening and diagnostic procedure and is easy to perform besides being economical, feasible and acceptable.

There were also some limitations in the study. Both tests were not conducted in the same subjects, hence accuracy in terms of sensitivity and specificity could not be compared in two groups. Second was maternal and fetal outcome was not considered so exact proportion of adverse perinatal outcome can be just predicted on the basis of previous studies and not the present study. In the two groups there were women who already had GDM in previous pregnancy so there existed selection bias in the study. Despite these limitations the study concluded positive role of universal screening by DIPSI.

\section{CONCLUSION}

With a huge population in reproductive age in India significant segment developing abnormal glucose tolerance is a matter of concern. Hence universal screening rather than selective should be recommended. Various tests are now-a-days available which can detect GDM beforehand and this may help to prevent perinatal morbidity associated with the condition. Present study concludes that DIPSI is the test which can predict GDM in population comparable to another test like OGTT. Also, India's major population reside in rural areas, ANC are mostly conducted by ANM, therefore screening test should be easy to perform and interpret. Moreover, knowledge regarding GDM to all pregnant women can increase acceptability which in turn can fulfil criteria of universal screening in this study population of reproductive age group. IGT should be considered as independent risk factor to develop GDM in future pregnancies. DIPSI may be the answer.

\section{Funding: No funding sources}

Conflict of interest: None declared

Ethical approval: The study was approved by the Institutional Ethics Committee

\section{REFERENCES}

1. Metzger BE, Coustan DR. Summary and recommendations of the fourth international workshopconference on gestational diabetes mellitus. The
Organizing Committee. Diabetes Care. 1998;21(Suppl 2):B161-7.

2. Seshiah V, Balaji V, Balaji MS, Pannerselvam A, Arthi T, Thamilarasi M, et al. Prevalence of GDM in South India (Tamilnadu). A community based study. J Assoc Physicians India. 2008;56:329-33.

3. Seshiah V, Balaji V, Balaji MS, Paneerselvam A, Arthi $\mathrm{T}$, Thamizharasi M, et al. Gestational diabetes mellitus in all trimesters of pregnancy. Diabetes Research Clin Prac. 2009;77:482-4.

4. Seshiah V. Fifth national conference of diabetes in pregnancy study Group, India. J Assoc Physicians India. 2010;58:329-0.

5. Xu X, Liu Y, Liu D, Li X, Rao Y, Sharma M, Zhao Y. Prevalence and determinants of gestational diabetes mellitus: a cross-sectional study in China. Int $\mathrm{J}$ Environ Res Public Health. 2017;14(12):1532.

6. Jiwani A, Marseille E, Lohse N, Damm P, Hod M, Kahn JG. Gestational diabetes mellitus: results from a survey of country prevalence and practices. The $\mathrm{J}$ Maternal-Fetal Neonat Med. 2012;25(6):600-10.

7. Sevket O, Ates S, Uysal O, Molla T, Dansuk R, Kelekci $\mathrm{S}$. To evaluate the prevalence and clinical outcomes using a one-step method versus a two-step method to screen gestational diabetes mellitus. The J MaternalFetal Neonat Med. 2014;27(1):36-41.

8. Sharma A, Gupta M, Agrawal A. Comparison of diagnostic accuracy of two one step procedures for screening of gestational diabetes mellitus. Int J Reprod Contracept Obstet Gynecol. 2015;4(1):81-5.

9. Balaji V, Balaji M, Anjalakshi C, Cynthia A, Arthi T, Seshiah V. Diagnosis of gestational diabetes mellitus in Asian-Indian women. Indian $\mathbf{J}$ Endocr Metab. 2011;15:187-90.

10. de Aguiar LG, de Matos HJ, de Brito Gomes M. Could fasting plasma glucose be used for screening high-risk outpatients for gestational diabetes mellitus ? Diabetes Care. 2001;24:954-5.

11. Mohan V, Mahalakshmi MM, Bhavadharini B, Maheswari K, Kalaiyarasi G, Anjana RM, et al. Comparison of screening for gestational diabetes mellitus by oral glucose tolerance tests done in the nonfasting (random) and fasting states. Acta Diabetol. 2014;51:1007-13.

12. Jowett NI, Samanta AK, Burden AC. Screening for diabetes in pregnancy: is a random blood glucose enough? Diabet Med. 1987;4:160-3.

13. Sermer M, Naylor CD, Farine D, Kenshole AB. The Toronto tri-hospital gestational diabetes project: A preliminary review. Diabetes care. 1998;21:B33.

Cite this article as: Khenwar D, Agarwal J,

Shrivastava S. Screening of gestational diabetes mellitus using one-step versus two-step method: a comparative study. Int J Reprod Contracept Obstet Gynecol 2020;9:3372-6. 